\title{
CASOS TRÁGICOS: UM LIMITE À RACIONALIDADE? ANÁLISE CRÍTICA DAS CONSIDERAÇÕES TECIDAS POR ATIENZA E LARIGUET SOBRE O ASSUNTO
}

\author{
Renato do Espírito Santo Rodrigues*
}

Resumo: O presente artigo pretende analisar a existência dos chamados "casos trágicos", conforme a formulação de Manuel Atienza e Guillermo Lariguet. Inicialmente, o artigo abordará a discussão a respeito dos hard cases para, num segundo momento, reconstruir os conceitos de Atienza e Lariguet para os casos trágicos. Em seguida, analisa-se a alegação de que os casos trágicos representariam um limite à racionalidade do discurso jurídico. Termina posicionando-se pela possibilidade de pelo menos uma resposta correta nesses casos, ressalvando a hipótese de previsão legal em alguns ordenamentos jurídicos que abriria espaço para julgamentos subjetivos e não fundamentados.

Palavras-chave: Teoria da argumentação jurídica. Casos trágicos. Casos fáceis. Casos difíceis. Racionalidade.

\section{TRAGIC CASES: A LIMIT TO THE RATIONALITY? CRITICAL ANALYSIS OF ATIENZA'S AND LARIGUET'S CONSIDERATIONS ABOUT THIS ISSUE}

\begin{abstract}
This article intends to analyse the so-called "tragic cases", according to the concept adopted by Manuel Atienza and Guillermo Lariguet. Firstly, this article will present the discussion on hard cases in order to examine their main features. Secondly, Atienza's and Lariguet's tragic case concepts will be analysed. Thirdly, it is discussed whether tragic cases imply a limit to rationality in legal discourses. Finally, it is presented a possibility of a correct answer in these cases, pointing out to the existence of legal orders which establish subjective judgements.
\end{abstract}

Keywords: Legal reasoning theory. Tragic cases. Easy cases. Hard cases. Rationality. 


\section{Introdução}

Charlie Gard, bebê britânico que não chegou a completar um ano de idade, sofria de uma rara doença genética que impedia as suas células de gerar a energia necessária para manter as suas atividades vitais ${ }^{1}$. Mal conseguia abrir seus olhos, diziam os médicos do hospital onde estava internado em Londres. Seu coração, cérebro e fígado haviam sido irremediavelmente afetados pela doença. Não se sabia se tinha dor. Os tribunais ingleses e a Corte Européia de Direitos Humanos, sediada em Estrasburgo, julgaram procedente o pedido dos médicos ingleses para que os aparelhos que mantinham artificialmente vivo o bebê fossem desligados, após desgastante processo judicial movido por seus pais, que insistiam na possibilidade de um tratamento alternativo. Em 28 de julho de 2017, após ser desligado o aparelho de respiração artificial, Charlie Gard morreu. Segundo os jornais da época, o caso suscitou questões como o direito à vida e os limites da intervenção dos pais e dos médicos.

Este bem poderia ser chamado um caso trágico por qualquer ângulo que se considere. É um caso trágico, no entanto, num sentido mais específico, aquele que ficou conhecido através da formulação do jusfilósofo espanhol Manuel Atienza: um caso em que qualquer solução importa o sacrifício de uma exigência essencial de um valor fundamental (ATIENZA, 1997, p.15) . Com efeito, no caso de Charlie Gard, estavam em colisão direta princípios jurídicos da maior relevância: de um lado, o direito à vida ; de outro, o direito à dignidade humana, pois os médicos insistiam que os danos já ocorridos eram irreversíveis e que não havia esperança de uma qualidade de vida mínima para o bebê, ainda que sobrevivesse. Quer se reconhecesse o direito a um outro tratamento experimental, ou não, um daqueles princípios restaria inapelavelmente vulnerado. Mais do que um “caso difícil”, que não encontra resposta imediata no ordenamento jurídico vigente, seria um dilema.

Ainda de acordo com Atienza, os casos trágicos seriam aqueles em que a racionalidade jurídica encontraria seus limites, pois não haveria possibilidade de "resposta correta”. Nesses casos, restaria ao juiz, então, abrir lugar para o sentimento do trágico no

\footnotetext{
*Mestrando em Direito na Universidade Federal de Juiz de Fora (MG), linha de pesquisa "Direito, Argumentação e Inovação”. Advogado.

${ }^{1}$ https://www.theguardian.com/uk-news/2017/jul/10/charlie-gard-key-questions-answered?CMP=share btn link https://www.theguardian.com/uk-news/2017/jul/10/charlie-gard-case-to-resume-on-thursday-after-tense-highcourt-hearing? CMP=share btn link
}

Revista de Teorias da Justiça, da Decisão e da Argumentação Jurídica | e-ISSN: 2525-9644 | Salvador | v. 4 | n. 1 | p. 119 - 136 | Jan/Jun. 2018 
Direito, sem que isso represente necessariamente um elemento perturbador ou disfuncional (ATIENZA, 1997, p.8). Já o filósofo argentino Guillermo Lariguet vai ainda mais longe ao advertir que a pretensão de racionalidade nesses casos não é outra coisa senão uma forma de irracionalidade.

O objeto do presente texto é tentar responder à seguinte ordem de perguntas: a) admitida atualmente a distinção casos fáceis/casos difíceis pelas teorias da argumentação de maior prestígio, seria factível falar também em casos trágicos? Caso positivo, quais seriam os seus traços principais? b) Representariam os casos trágicos um limite à racionalidade? Nessa linha, o corrente artigo pretende se contrapor às colocações de Manuel Atienza e Lariguet, não obstante a sedutora argumentação por eles apresentada. A tese a ser aqui defendida é no sentido de que os chamados “casos trágicos” implicam uma escolha difícil, em que necessariamente um valor fundamental de peso abstrato máximo se vê gravemente afetado; nada obstante, haveria, sim, a possibilidade de uma resposta “correta”, vale dizer, uma decisão judicial racional e objetivamente controlável em termos discursivos, na linha do que preconizou Cláudia Toledo, em artigo publicado no XXVIII Congresso Mundial do IVR (Lisboa, 2017). Mais além, aqui se defenderá o ponto de vista de que há somente um caso em que o Direito de alguns países abre conscientemente espaço para a ampla subjetividade do julgador - o julgamento pelo tribunal do júri - e, ainda assim, sob condições bastante estritas.

Para realizar tal tarefa, isto é, demonstrar a possibilidade de um discurso jurídico racional nas decisões de “casos trágicos”, intentar-se-á caracterizá-los e conceituá-los, descortinando os seus principais traços. Antes, porém, será necessário adentrar na polêmica em torno da caracterização dos casos fáceis e dos casos difíceis. Em seguida, abordar-se-á a posição de Manuel Atienza e Lariguet - este último porque aprofundou o questionamento de Atienza e porque apresentou algumas das que seriam características adicionais dos casos trágicos. Ato contínuo, passar-se-á à fundamentação da tese aqui esposada, com base no conceito de Direito e na teoria da argumentação jurídica veiculados por Robert Alexy.

\section{Casos fáceis, casos difíceis}

Inicialmente, trata-se de trazer à baila a tradicional diferenciação feita na dogmática jusfilosófica a propósito de easy cases e hard cases, para, a partir dessa base conceitual, investigar a possível existência de casos trágicos. Não apenas isso, deve-se perguntar mesmo se há relevância ou utilidade em tal distinção.

Revista de Teorias da Justiça, da Decisão e da Argumentação Jurídica | e-ISSN: 2525-9644 | Salvador | v. 4 | n. 1 | p. 119 - 136 
Nesse plano, entende-se que a distinção entre hard cases e casos fáceis é relevante e útil e não apenas para viabilizar, ou não, a identificação de casos trágicos. De fato, tentar responder à questão da identificação de “casos difíceis” pode ser o primeiro passo para responder a outra: como julgá-los? Com isso, estaria aplainado o caminho para o exame dos casos trágicos, pois, como se verá mais adiante, o procedimento a ser adotado seria o mesmo.

Não é de hoje que a Filosofia do Direito vem debatendo as possíveis características de casos difíceis. Para esse efeito, não é inútil recordar o debate entre Ronald Dworkin e H.Hart. Para os positivistas, o julgador estaria inapelavelmente cingido à autoridade do direito positivo. Todavia, eventualmente desamparado de lei ou precedente que ensejasse a aplicação simples e direta do direito ao caso concreto, estaria o juiz autorizado a "criar" uma regra jurídica específica, desde que o fizesse dentro da "moldura” do Direito. Já não se tratava, então, de mera aplicação do modelo silogístico, mas de verdadeira atividade criativa do juiz, através da discricionariedade. Percebe-se, então, com facilidade que já para os positivistas assumia um caráter vital descortinar quando se estivesse diante de um caso difícil, pois esta seria a janela aberta para que o juiz agisse como legislador.

Contra essa visão é que se insurgiu Dworkin. Para ele, mesmo nos hard cases, incumbiria ao juiz "descobrir" o bom direito, fazendo pender a balança da Justiça em favor de um dos litigantes, com base em princípios coerentes com toda a história do instituto jurídico em análise, de forma integrada. Hard cases não seriam diferentes em substância dos "casos fáceis”. O método a ser aplicado seria o mesmo e a resposta correta seria única (DWORKIN, p.81).

Com tal assertiva concordam, por exemplo, Ariza e MacCormick: a distinção não estaria no método, pois a dedução no modelo silogístico seria aplicável de todo modo. A diferença entre um caso fácil e um caso difícil residiria no grau de dificuldade para o estabelecimento das premissas, sejam elas normativas ou fáticas (ARIZA, p.299). A respeito da primeira hipótese, esclarece Ariza que a dificuldade poderia se originar de uma omissão legislativa, ou de um problema de identificação da norma aplicável; já a propósito da segunda hipótese, a dificuldade estaria na produção da prova do fato ou, mesmo, na sua qualificação jurídica. Mas, admitidas as premissas normativas e fáticas, o tratamento a ser conferido ao caso não seria diferente.

Revista de Teorias da Justiça, da Decisão e da Argumentação Jurídica | e-ISSN: 2525-9644 | Salvador | v. 4 | n. 1 | p. 119 - 136 
Para outros autores, todavia, casos fáceis seriam resolvidos de acordo com critérios de racionalidade estrita, enquanto que os casos difíceis demandariam um critério mais flexível, do tipo "razoabilidade”, a ser aplicado em caráter subsidiário ao primeiro critério. Ditas decisões razoáveis deveriam buscar um equilíbrio ótimo entre os princípios colidentes e o máximo de consenso racional (ATIENZA, 1989, p.100).

Para Cláudia Toledo, “casos difíceis” podem ocorrer quando as normas do direito positivo não são claras; quando as normas conflitam umas com as outras; ou quando o direito positivo contém alguma omissão sobre o tema a ser julgado. Na primeira hipótese, o remédio seria lançar mão dos métodos hermenêuticos (gramatical, histórico, sistemático, teleológico); na segunda hipótese, o intérprete deveria se valer dos critérios cronológico, hierárquico ou da especialidade, se se tratasse de conflito entre regras; e da máxima da proporcionalidade, se se tratasse de princípios. Por fim, para sanar lacunas legislativas, poderia o intérprete ou julgador recorrer ao próprio direito positivo (no caso, a analogia) ou ao discurso prático geral fundamentos morais, éticos ou pragmáticos (TOLEDO, 2017, p.2).

Para Alexy, o discurso jurídico é um caso especial do discurso prático geral. Assim, eventualmente impossibilitado de obter no primeiro a resposta a um determinado caso (o que costuma ocorrer nos hard cases), sempre restaria ao julgador recorrer ao repositório de fundamentos do discurso prático geral (ALEXY, 2009, p.24).

Dito isto, deve-se agora procurar as respostas às perguntas inicialmente colocadas, vale dizer: o que são casos difíceis? Como julgá-los? Para esse efeito, então, reputa-se que, nos “casos fáceis”, o material disponível no direito positivo é suficiente, por si só, para a sua solução. Nesses casos, a mera subsunção da hipótese à regra será bastante para encontrar uma solução “correta”. A racionalidade é satisfeita pela observância da lógica (justificação interna) e não há dificuldade em estabelecer as premissas normativas ou fáticas (justificação externa).

Nos chamados “casos difíceis”, ao revés, o direito positivo não teria uma resposta disponível de maneira imediata, à mão, seja por incompletude do ordenamento, seja por conflito de normas ou, ainda, por simples vagueza ou ambiguidade. Pode ser, também, que a dificuldade no julgamento do caso decorra da incerteza quanto às suas premissas empíricas, seja em termos de realização da sua prova, seja em termos de classificação jurídica. Por aí já se vê que se justifica plenamente a investigação a respeito de tais casos, porque, a depender da classificação, a metodologia para o seu julgamento seria diferente. Para solucionar um hard case pode ser necessário, portanto, lançar mão dos métodos hermenêuticos, das presunções, 
de analogia, regras de prioridade das fontes do Direito, ponderação de princípios ou, ainda, de substratos do discurso prático geral - fundamentos morais, éticos ou pragmáticos.

Contemplada a distinção entre casos fáceis e casos difíceis sob esta perspectiva, entende-se possível enquadrar os casos trágicos como uma modalidade de hard case, porquanto presente a incerteza quanto às premissas normativas e/ou fáticas.

\section{A visão de Manuel Atienza sobre os casos trágicos}

A presente análise tomará por referência dois textos de Manuel Atienza: “Sobre lo razonable en el derecho" (ATIENZA, 1989) e “Los límites de la interpretación constitucional: de nuevo sobre los casos trágicos” (ATIENZA, 1997). Em dois momentos diferentes, o autor em tela abordou a existência de casos trágicos, exprimindo naquelas ocasiões visões diferenciadas.

No primeiro texto, “Sobre lo razonable en el derecho", pode-se dizer que o tema “casos trágicos” assume um papel secundário no desenvolvimento do tema principal. Assim é que, ao tecer considerações sobre a ponderação de princípios ou valores, Atienza salienta que haveria uma terceira categoria de casos - além dos chamados “casos fáceis” e “casos difíceis” -, os “casos trágicos”, a propósito dos quais “no existe ninguna solución que se sitúe por encima del equilibrio mínimo”. Nesses casos, o intérprete já não estaria frente a uma simples alternativa, senão a um dilema (ATIENZA, 1989, p.101). Em tais contextos, o julgador poderia lançar mãos dos mesmos recursos admitidos para a resolução dos hard cases, com a diferença de que, nos casos trágicos, não seria possível garantir um equilíbrio “ótimo” entre os valores conflitantes. Ao contrário, o resultado da ponderação seria, inevitavelmente, o sacrifício de “algo esencial” (ATIENZA, 1989, p.104). Nesse quadro, falar em "razoabilidade” somente seria possível num sentido "muito débil”.

Mas, o que representaria o tal sacrifício de um princípio ou valor? Em que medida se poderia falar em perda de algo essencial? No segundo texto - Los límites de la interpretación constitucional: de nuevo sobre los casos trágicos” - , Atienza busca esclarecer tais perguntas. Para esse autor, valores fundamentais impõem exigências para o seu cumprimento. Algumas dessas exigências são essenciais (embora isso não fique claro, presume-se que se trata daquelas que, eventualmente ausentes, descaracterizariam totalmente o valor) e outras, não. Em regra, as exigências do mesmo valor seriam compatíveis (ATIENZA, 1989, p.99). Pode ocorrer, todavia, colisão entre exigências de valores diferentes. Nos casos difíceis, por

Revista de Teorias da Justiça, da Decisão e da Argumentação Jurídica | e-ISSN: 2525-9644 | Salvador | v. 4 | n. 1 | p. 119 - 136 
exemplo, o objetivo seria encontrar um equilíbrio entre valores considerados fundamentais pelo ordenamento jurídico, de modo a satisfazer, no mínimo, as exigências essenciais de tais valores (equilíbrio mínimo) e, no máximo, também algumas de suas exigências não essenciais (equilíbrio ótimo). Nos casos trágicos, ao revés, seria impossível deixar de sacrificar alguma exigência essencial de um valor considerado fundamental "desde el punto de vista jurídico y/o moral". Aqui, o julgador estaria diante de um dilema em que a racionalidade seria um recurso insuficiente. Restaria ao intérprete, então, “dejar un lugar para el sentimiento de lo trágico en el Derecho” (ATIENZA, 1997, p.15).

Nesse ponto, é inevitável a conclusão de que o posicionamento de Atienza se distancia das chamadas teorias standard da argumentação: o próprio autor o reconhece (ATIENZA, 1997, p.14 e 16). Para aquelas teorias, afinal, sempre seria possível encontrar ao menos uma resposta correta para cada caso, mesmo para os hard cases. Ou seja, sempre seria válido o recurso à razão. Para Atienza, todavia, os filósofos morais (Ricoeur e Murgueza, por exemplo) estariam mais abertos à possibilidade de "escolhas trágicas", ao contrário dos filósofos do direito, os quais, no fundo, estariam desnecessariamente apegados à infalibilidade das fórmulas jurídicas tradicionais das democracias ocidentais ("o melhor dos mundos existentes, mas não o melhor dos mundos ideais”). Por isso, julgou indispensável dar um passo adiante em relação à definição que anteriormente dera (em "Lo razonable en el derecho) e abrir espaço para o reconhecimento do trágico na experiência jurídica, sem que isso represente, por si só, algo negativo, porquanto poderia cumprir uma função importante, na medida em que o sentimento de pesar com o qual teria que conviver o juiz poderia motiválo a evitar que surgissem, no futuro, outras "situaciones dilemáticas”:

Aplicado al caso de los jueces (y de los operadores jurídicos en general), la conciencia de lo trágico - y el sentimiento de malestar que lo acompaña puede muy bien servir de revulsivo para incitar al juez a cumplir con sus deberes como ciudadano, esto es, con su deber de contribuir a modificar el mundo social de manera que disminuya lo trágico en el Derecho (en ese sentido, cabe decir que no se puede ser buen juez si no se es también un buen ciudadano). Entre tanto, quizás no esté de más recordar que si hay algo de cierto en el famoso aserto del juez Holmes de que 'la vida del Derecho no ha sido lógica, sino experiencia’ [1963, p.5], quizás no lo haya menos en la frase de Unamuno de que 'la vida es tragedia, y la tragedia es perpetua lucha, sin victoria ni esperanza de ella; es contradicción’ [1994, p.58]. Y si

Revista de Teorias da Justiça, da Decisão e da Argumentação Jurídica | e-ISSN: 2525-9644 | Salvador | v. 4 | n. 1 | p. 119 - 136 
esto es así, es muy probable que no tengamos ninguna razón para prescindir de la experiencia de lo trágico en el Derecho” (ATIENZA, 1997, p.28).

Não obstante a vislumbrada impossibilidade de uma decisão “correta” nos casos trágicos, Atienza entende que isto não implica a inviabilidade por completo de algum controle racional (ATIENZA, 1997, p.25). Poderia o juiz recorrer a “critérios de razoabilidade”, algo que se situasse entre a racionalidade estrita e a pura e simples arbitrariedade (ATIENZA, 1997, p.26). Uma decisão, enfim, que implicaria acudir a “otros ámbitos de la razón práctica".

Como se vê, a posição do ilustre jusfilósofo espanhol a respeito dos casos trágicos mudou ao longo do tempo: partindo do que chamou uma definição “algo ambígua”, em que se reconhecia a vulneração de algum valor fundamental no sistema, chegou a uma crítica também ambígua das possibilidades do discurso racional. Justamente este último ponto é que motivou o texto de Lariguet, que será abordado no próximo tópico.

\section{A visão de Guillermo Lariguet sobre os casos trágicos}

No texto "Conflictos trágicos genuinos, ponderación y límites de la racionalidad jurídica: en torno a algunas ideas de Manuel Atienza”, o filósofo argentino Guillermo Lariguet situa sua crítica a Atienza no fato de que o jusfilósofo espanhol não teria levado sua posição a respeito dos casos trágicos às últimas consequências. De acordo com o filósofo da Universidade de Córdoba, faltou a Atienza reconhecer o consectário de sua afirmação sobre a inviabilidade de uma resposta “correta” em tais situações. Para ele, e seguindo a linha de Jon Elster, "la racionalidad tiene límites y que no advertirlo es una forma más de irracionalidad”. Ao assim se posicionar, Lariguet inequivocamente vai de encontro a um postulado admitido pela corrente dominante na teoria da argumentação, cujos próceres estariam imbuídos do "noble dream" mencionado por H.L.A. Hart: "the belief, perhaps the faith, that, ...still an explanation and a justification can be provided for the common expectation of litigants... (HART, p.978). Para a maioria dos juristas e dos filósofos do direito, prossegue Lariguet, a investigação dos chamados “casos trágicos” simplesmente não estaria em jogo e, ainda que admitidos, deveriam ser confinados à sua mínima expressão. E isso ocorreria porque a maioria dos sistemas jurídicos atuais impõem aos juízes uma obrigação indeclinável de entregar uma decisão, por mais difícil que o caso seja.

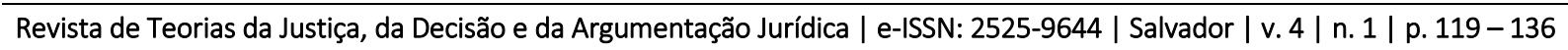


O ponto central da crítica de Lariguet está focado em que não se deve confundir a proposta racional com a sua real possibilidade de implementação. Nesse sentido, não bastaria admitir os limites da ponderação, por exemplo. Haveria que reconhecer que, em alguns casos, realmente não seria possível à razão obter uma resposta "correta”: “ Aun si hay un desarrollo sofisticado de mecanismos de resolución racional de conflictos entre principios, no debería confundirse la existencia de estos mecanismos con la existencia real de los conflictos” (LARIGUET, p.100).

Ainda para o filósofo argentino, a natureza trágica de determinado conflito pode decorrer da "incomensurabilidade" ou da "insuperabilidade" dos valores envolvidos e traz à tona os limites da ponderação de princípios. Restaria ao intérprete ou julgador franquear espaço para o "sentimento" ou para as “paixões serenas”, em direção a algum dos valores colidentes (LARIGUET, p.103).

Pois bem. Para Lariguet, Atienza teria partido de um diagnóstico correto, porém as conclusões a que chegou ficariam aquém das premissas adotadas, porque ao final teria sucumbido à tentação racionalista de admitir que sempre seria possível, mesmo nos casos trágicos, chegar a uma solução “menos pior”. Alguma forma de controle racional do resultado ainda seria viável, de acordo com Atienza. Ora, isso viria de encontro ao próprio diagnóstico que efetuara:

No obstante, aun si lo hiciera, su idea de que hay casos trágicos genuinos sería liquidada pues ahora lo que uno llama 'trágico' no sería más que el nombre de algo meramente aparente. Pero si es así, su argumento de que no es posible prescindir de la experiencia de lo trágico en el derecho termina avalando una posición un tanto cándida. La expresión ‘casos trágicos’podría, en esta vena, ser sustituida sin pérdida de significado por la expresión 'casos difíciles', con lo cual la distinción que Atienza efectuara en el trabajo citado entre ambos tipos de casos sería borrada (LARIGUET, p.103).

Segundo Lariguet, o intérprete deveria abandonar qualquer esperança de obter uma resposta correta para os casos trágicos em qualquer domínio, inclusive no âmbito daquilo que genericamente se chama “racionalidade prática” (LARIGUET, p.105).

\section{Casos trágicos: uma possibilidade de resposta correta}

Revista de Teorias da Justiça, da Decisão e da Argumentação Jurídica | e-ISSN: 2525-9644 | Salvador | v. 4 | n. 1 | p. 119 - 136 
De tudo que foi aqui exposto depreende-se que, grosso modo, as críticas à possibilidade de uma resposta racional nos casos trágicos derivam, em última análise, da inviabilidade de ponderação dos valores em jogo. E aqui entram em cena alegações recorrentes nesse tipo de visão: $a$ ) os valores colidentes seriam incomensuráveis; $b$ ) os valores em conflito seriam "insuperáveis" (em nossa tradução do texto em espanhol “inderrotables”); c) o ponto de equilíbrio em tais casos ficaria abaixo do mínimo, pois alguma exigência essencial de um valor fundamental restaria sacrificada; $d$ ) ao invés da racionalidade estrita, mais recomendável seria lançar mão, nos casos trágicos, dos critérios da razoabilidade. Trata-se, então, de examiná-las e verificar a sua pertinência. Como as alegações estão entrelaçadas (por exemplo, a incomensurabilidade decorrendo da própria insuperabilidade do valor, e esta última, por sua vez, implicando a tragédia de eventual sacrifício de uma exigência essencial), a análise será feita de maneira global, tendo como referência o conceito de Direito, a ponderação de princípios e a tese do caso especial, tal qual formulados por Robert Alexy.

Nessa ordem de ideias, é importante não perder de vista que a preconizada ponderação envolve, em verdade, três aspectos: a lei da ponderação, a fórmula do peso e a carga da argumentação (PULIDO, p.8).

Como se sabe, a lei da ponderação estabelece que “quanto maior o grau de não cumprimento ou de restrição de um princípio, maior deve ser a importância do cumprimento do outro" (ALEXY, 2008).

A fórmula do peso, por sua vez, implica o detalhamento da estrutura da ponderação, de modo que restem transparentes os fatores envolvidos, bem como a argumentação que lhes serve de suporte. Nessa linha, afirma Alexy que os fatores da fórmula do peso correspondem, respectivamente a cada princípio, à intensidade da interferência ou da sua não satisfação (I); ao seu peso abstrato $(W)$; e à certeza das premissas, fáticas ou normativas, que justificam a interferência $(R)$ :

$$
W_{i, j}=\frac{I_{i} \cdot W_{i} \cdot R_{i}}{I_{j} \cdot W_{j} \cdot R_{j}}
$$

Revista de Teorias da Justiça, da Decisão e da Argumentação Jurídica | e-ISSN: 2525-9644 | Salvador | v. 4 | n. 1 | p. 119 - 136 
Nesse ponto, releva anotar que o mérito da fórmula do peso consiste não propriamente em fornecer uma solução “matemática” (no sentido de completamente exata) para as colisões de princípios, mas sim em consistir num instrumento para explicitar os argumentos utilizados a favor ou contra de determinada interpretação. Como resultado, espera-se um ganho na transparência e na racionalidade do processo.

Certa crítica parte do pressuposto de que os valores conflituosos são incomensuráveis quando não é possível adotar uma métrica comum de valoração (LARIGUET, p.93). Não haveria, por consequência, como compará-los e apurar seus pesos relativos, por falta de um padrão comum com o qual confrontá-los. Assim é, por exemplo, nos casos em que se confrontam princípios como vida humana e dignidade humana - como ocorre, aliás, no caso do bebê Charlie Gard. Certificada a incomensurabilidade, a aplicação da fórmula do peso ficaria prejudicada, de acordo com esse argumento. Conforme Virgílio Afonso da Silva, na base dessa argumentação estaria um receio de vulneração dos direitos fundamentais nos pronunciamentos judiciais (SILVA, p.275).

Para esse efeito, reputa-se conveniente de plano chamar a atenção para o fato de que a pluralidade de valores avistada por Aristóteles é algo imanente à natureza humana (LA FUENTE, p.9). Dignidade, liberdade, honra, igualdade (sem falar no próprio direito à vida, que é base de todos os outros) são valores não intercambiáveis entre si. Sem eles, não se pode falar propriamente de respeito à pessoa. Não se afigura factível abrir mão de um deles em benefício de outro valor. Nós, seres humanos, precisamos deles todos, desde o nascimento e até a morte. Bem por isso, costuma-se falar que, em abstrato, podem os valores fundamentais ter o mesmo peso, porquanto se presume que, se métrica houvesse, haveriam de ser contemplados com o mesmo grau. Nem por isso se deixa de atribuir um peso abstrato para cada princípio colidente. Ademais, incomensurabilidade não é o mesmo que incomparabilidade. Se não é possível atribuir um "grau” numérico a determinado princípio, pode ser possível compará-lo com outro princípio, à luz do caso concreto, de modo a determinar aquele que merece prevalecer. Por esse aspecto, a alegada incomensurabilidade não seria obstáculo à ponderação. Para Virgílio Afonso da Silva, aliás, o que importa é que exista base para comparação “relative to a covering or choice value” (SILVA, p.284) e que a ponderação se dê no caso concreto. Nesse ponto, vale a pena esmiuçar o que seria "covering or choice value".

Revista de Teorias da Justiça, da Decisão e da Argumentação Jurídica | e-ISSN: 2525-9644 | Salvador | v. 4 | n. 1 | p. 119 - 136 
No mesmo artigo, SILVA exemplifica com uma possível comparação entre a música produzida por Madonna e por Bach. Em termos genéricos, fica realmente difícil compará-los. Mas à medida que se adotam parâmetros mais precisos, algum tipo de comparação torna-se possível. Por exemplo, as respostas poderão variar caso se indague a respeito da "contribuição para a cultura musical ocidental” ou da “adequação para dançar em boates” (SILVA, p.284).

No campo da Economia, não se desconhece o conceito de trade-off (MANKIEW) quando os recursos são escassos, e uma decisão deve necessariamente ser feita, há que se fazer escolhas: seja como um estudante utilizará o tempo disponível para estudar para uma prova, seja o tipo de despesa que uma família terá nas férias de verão (ficar em casa e economizar para o material escolar, viajar para o exterior ou conciliar as opções, fazendo uma viagem mais barata?). Como se vê, é possível comparar coisas diversas - aliás, estamos sempre fazendo isso.

O mesmo se diga em relação a uma suposta "insuperabilidade" de determinados valores (“inderrotables”), com o acréscimo de que o eventual sacrifício de um deles somente poderia ser cogitado diante das peculiaridades do caso concreto. Com efeito, afigura-se inviável de plano vislumbrar a preponderância em tese de algum deles - mesmo o direito à vida, porque não seria absurdo admitir que, em determinadas situações, alguém descartasse continuar uma vida sem dignidade, por exemplo. Desse modo, admitida a ponderação, conforme a fórmula alexyana de peso, não há negar que o peso abstrato de tais valores deve ser necessariamente igual (ou seja, no grau máximo), mesmo que isso implique a possibilidade de um “empate”. Nesse sentido, vale transcrever o entendimento de Cláudia Toledo:

In alexyan terms, in tragic cases there is a collision of principles with the heaviest abstract weight in the legal system. No matter the decision, according to the law of balancing, there will be an extremely serious interference or the sacrifice of one of this principles. This is the classical example of a stalemate in the weight formula (TOLEDO, p.3).

Pode ocorrer, então, que as peculiaridades do caso venham a acarretar a atribuição de um grau maior de interferência de determinado princípio em outro, por maior que seja o peso abstrato de que desfrutem. Acresce que, na atribuição do grau de intensidade da afetação dos princípios, o intérprete ou julgador deverá avaliar as circunstâncias fáticas em conformidade 
com as escolhas axiológicas que eleger, fazendo-o de modo fundamentado. Assim, desde que isso ocorra de modo fundamentado, caberá decidir a lide em favor daquele que estiver amparado nas melhores razões.

Trazendo tais conceitos ao caso Charlie Gard, entende-se que os pesos abstratos dos princípios fundamentais em jogo se equivaliam (vida e dignidade humana). O mesmo pode-se dizer em relação à certeza quanto às premissas fáticas, pois não havia dúvida quanto à irreversibilidade da condição física do menor. O que terminou por fazer a diferença foi realmente o grau anotado da interferência nos princípios colidentes - no caso, a eventual sobrevivência do bebê não lhe garantiria condições dignas mínimas, dada a extensão dos danos físicos que experimentou:

In our judgment, the intellectual milestones for the judge in a case such as the present are, therefore, simple, although the ultimate decision will frequently be extremely difficult. The judge must decide what is in the child's best interests. In making that decision, the welfare of the child is paramount, and the judge must look at the question from the assumed point of view of the child. There is a strong presumption in favour of a course of action which will prolong life, but that presumption is not irrebuttable. The term "best interests" encompasses medical, emotional, and all other welfare issues.'

"Charlie's parents have, sadly but bravely, acknowledged and accepted that the quality of life that Charlie has at present is not worth sustaining, for he can only breathe through a ventilator and, although they believe that he has a sleep/wake cycle, and can recognise them and react to them when they are close, they realise that he cannot go on as he is, lying in bed, unable to move, fed through a tube, breathing through a machine. ${ }^{2}$

Nessa linha, é interessante ressaltar que a necessária valoração adotada por um tribunal na eleição do princípio ou valor que se julgou preponderante não exclui a racionalidade da decisão, desde que isso ocorra de modo transparente. Afinal, sendo o

2

${ }^{\natural}$ Case no: FD17P00103, Justice Francis, Great Ormond Street Hospital and Charlie Gard, Royal Courts of Justice, High Court, Family Division.

Revista de Teorias da Justiça, da Decisão e da Argumentação Jurídica | e-ISSN: 2525-9644 | Salvador | v. 4 | n. 1 | p. 119 - 136 
discurso jurídico um caso especial do discurso prático, o seu objeto corresponderá sempre ao que é “bom” ou "devido” nas questões práticas que se apresentarem. E assim, voltando o julgador os seus olhos para o discurso prático geral, nada mais natural que venha a contemplar os substratos morais, éticos e pragmáticos envolvidos. O julgador, enfim, como anota Aarnio, não está isento de declinar a tábua de valores em que se baseou:

If it is possible to justify an interpretative position on a rational basis in a satisfactory manner by using any value system whatsoever, every decision would then be justified. After all, it is rational, and it is based on some value code. Thus we can "rationally"present arguments for interpretation on the basis of the value system we have adopted. It is "just as good"a position as is another interpretation, which is built on the basis of a different value code (AARNIO, p. 220).

Como se observa, o método a ser adotado na solução de “casos trágicos” em nada diferiria daquele preconizado para a resolução de hard cases - isto é, ponderação de princípios. Nem mesmo o eventual sacrifício integral de algum desses princípios, ao final e ao cabo da ponderação, seria motivo para descartá-la, eis que garantido o crivo da argumentação racional. Nesse sentido, não é teoricamente útil a cogitada diferença em relação aos "casos difíceis” - em que supostamente haveria um equilíbrio “ótimo” entre os princípios conflitantes. É que nem mesmo em hard cases seria possível descartar a priori a possibilidade de sacrifício integral de algum deles. Não há falar, então, em equilíbrio “mínimo”. Ademais, careceria de precisão científica a alusão a sacrifício de exigências essenciais de valores fundamentais. Como distinguir uma exigência fundamental de uma não-fundamental?

Por fim, analisa-se a asserção de que nos “casos trágicos” somente seria possível falar em razoabilidade num sentido “más bien débil” (ATIENZA, 1989, p.104). De acordo com Atienza,

Ciertamente, en tales contextos podrían utilizarse nas mismas reglas que en los casos simplemente difíciles (por ejemplo, la de no sacrificar ninguna exigencia de rango superior en aras de alguna(s) de rango inferior), pero lo que cambia es que ahora la decisión no puede pretender ser equilibrada, en cuanto que se ha sacrificado algo esencial. En definitiva, una decisión en tales contextos sería razonable tan sólo en el sentido de que se pueden dar razones en favor de sua adopción que son mejores que otras. La justificación

Revista de Teorias da Justiça, da Decisão e da Argumentação Jurídica | e-ISSN: 2525-9644 | Salvador | v. 4 | n. 1 | p. 119 - 136 


\section{CASOS TRÁGICOS: UM LIMITE À RACIONALIDADE? ANÁLISE CRÍTICA DAS CONSIDERAÇÕES TECIDAS POR ATIENZA E LARIGUET SOBRE O ASSUNTO}

sería, cabría decir, tan sólo relativa: la decisión en cuestión no es buena, pero es la mejor posible (ATIENZA, 1989, p.104).

Como visto acima, o eventual desequilíbrio na ponderação de princípios, com o sacrifício de algum deles, não é motivo para descartar a priori a racionalidade da decisão. Aliás, não é raro que tal sacrifício aconteça, dada a inviabilidade, no caso concreto, da subsistência de um dos princípios envolvidos. Nem por isso seria o caso de se falar numa razoabilidade "débil”, muito menos na impossibilidade de uma decisão "correta”. Nesse plano, importa salientar que a pedra de toque da questão está no fato de que o que existe, na verdade, é uma "pretensão de correção", mesmo nos hard cases, e a pretensão não admite gradação - ou se afirma, ou se nega. Esse o ponto para o qual chamou a atenção Cláudia Toledo:

The quality of the justification of the decision is optimizable. The correctness is not, because it is not a quality, but a claim. Claim has no grades, either it is satisfied or not. Therefore, the claim to correctness must necessarily be satisfied for the decision to be correct (TOLEDO, p.5).

Ora, a pretensão de correção é inerente ao conceito de Direito. Ao contrário dos positivistas, que vislumbram naquele conceito apenas uma dimensão fática, que compreende a produção jurídica formalmente adequada e a eficácia social, os não positivistas (Alexy, entre eles) entendem que há que associar também uma dimensão ideal, baseada numa pretensão de correção derivada da própria natureza do discurso jurídico e que, como tal, é necessária. Como demonstrou Alexy, resultaria absurdo um pronunciamento judicial ou legal que admitisse, ainda que implicitamente, a cláusula de injustiça (ALEXY, 2009, p.12). Afinal, um pronunciamento em tais condições entraria em contradição com a própria pretensão de correção que advém de sua natureza enquanto caso especial do discurso prático geral - o qual, por finalidade intrínseca, se direciona à solução de “questões práticas” em direção aos valores do Justo e do Bem.

Nesse quadro, não faz muito sentido mesmo imaginar que a saída nos "casos trágicos” estaria em abrir espaço para a expressão do sentimento, ou das “paixões serenas” (HUME, 2009, p.473). Partindo do pressuposto que a racionalidade jurídica é discursiva, e presente uma fundamentação baseada nas regras fundamentais e da razão prática, da carga de 
argumentação e das formas de justificação externa, com explicitação das opções valorativas adotadas, motivo não há para supor a inviabilidade de ao menos uma resposta “correta”.

Avista-se que há somente um caso em que alguns ordenamentos jurídicos contemplam a possibilidade de um julgamento não fundamentado e, portanto, aberto a avaliações subjetivas - as decisões do Tribunal do Júri. Assim é, por exemplo, no caso do direito brasileiro, seja por expressa previsão constitucional - art. $5^{\circ}$, inciso XXXVIII -, seja por força da legislação de regência - Código de Processo Penal, art. 483.

Com efeito, os mencionados dispositivos estabelecem não apenas o sigilo das votações dos jurados - que somente precisam responder afirmativa ou negativamente aos quesitos apresentados -, mas também a soberania dos vereditos. Assim, caso a maioria dos jurados entenda que o réu deve ser absolvido, mesmo que reconhecida a materialidade do fato e a autoria ou participação, não poderá haver condenação. Os jurados sequer precisarão justificar a decisão. Daí decorre, então, a falta de controle da racionalidade do julgamento, o qual bem poderá ficar (e, muitas vezes, ficará) ao sabor das avaliações subjetivas dos jurados. Esse também o sistema adotado em países como Estados Unidos e França. Não assim, porém, nos procedimentos do Tribunal do Júri de Portugal e Espanha, por exemplo, em que há necessidade de fundamentação das respostas dadas aos quesitos.

\section{Conclusão}

Um dilema, quando posto em juízo, não significa necessariamente a inviabilidade de ao menos uma resposta “correta”. A decisão sempre poderá ser justificada discursivamente, com explicitação das variáveis preponderantes e dos valores prestigiados, por mais relevantes sejam os direitos fundamentais envolvidos e o peso abstrato de que desfrutem. A racionalidade e a objetividade dos pronunciamentos judiciais não podem ser descartadas. É assim nos hard cases e, também, nos “casos trágicos”. A exceção ficaria por conta dos ordenamentos jurídicos que contemplam o julgamento não fundamentado (e, portanto, sem possibilidade de controle racional) no rito do Tribunal do Júri, como ocorre no caso brasileiro.

No caso “Charlie Gard”, não obstante a dramaticidade das circunstâncias que o envolveram, o Tribunal inglês terminou por justificar motivadamente a opção adotada difícil, sem dúvida, mas ainda assim portadora de razões morais relevantes, gostando-se delas

Revista de Teorias da Justiça, da Decisão e da Argumentação Jurídica | e-ISSN: 2525-9644 | Salvador | v. 4 | n. 1 | p. 119 - 136 
ou não. De todo modo, parece mesmo inevitável nesses casos o sentimento de pesar do julgador, ou “remordimiento”, como a ele se referiu Lariguet.

\section{REFERÊNCIAS BIBLIOGRÁFICAS}

AARNIO, Aulis. The rational as reasonable: a treatise on legal justification. Dordrecht, Holland: D.Reidel Publishing Company, 1986.

ALEXY, Robert. Princípios formais e outros aspectos da teoria discursiva do Direito. Rio de Janeiro: Forense Universitária, 2014.

Principais elementos de uma teoria da dupla natureza do direito. Do original

Hauptelemente einer Theorie der Doppelnatur des Rechts, publicado em Archiv für Rechts und Sozialphilosophie, v.95, n.2, p.151-166, abr.2009. Tradução de Fernando Leal.

Teoria da argumentação jurídica: a teoria do discurso racional como teoria da justificação jurídica. Tradução de Zilda Hutchinson Schild Silva; revisão técnica da tradução e introdução à edição brasileira: Cláudia Toledo. 2.ed. São Paulo: Landy Editora, 2005.

ARIZA, Santiago Sastre. Sobre la dificultad de los llamados casos fáciles, difíciles y trágicos. Derecho y Opinión, p. 295-306, 1993.

ATIENZA, Manuel. Sobre lo razonable en el derecho. Revista Española de Derecho Constitucional, Año 9, n.27, septiembre-diciembre 1989. Los limites de la interpretación constitucional: de nuevo sobre los casos trágicos.

Revista Isonomía, n.6, abril 1997.

DWORKIN, Ronald. Taking Rights Seriously. Harvard University Press, Cambridge, Massachusetts, 1977.

HART, Herbert. American jurisprudence through english eyes: the nightmare and the noble dream.

Georgia Law Review, vol. 11, september 1977, n.5.

HUME, David. Tratado da Natureza Humana: uma tentativa de introduzir o método experimental de raciocínio nos assuntos morais. Tradução: Debora Danowski $-2^{\circ}$ ed. rev. e ampliada. São Paulo: Editora UNESP, 2009.

Revista de Teorias da Justiça, da Decisão e da Argumentação Jurídica | e-ISSN: 2525-9644 | Salvador | v. 4 | n. 1 | p. 119 - 136 
LA FUENTE, Oscar Pérez de. Una aproximación aristotélica a la deliberación en casos trágicos. Madrid: Universidad Carlos III, Cuadernos electrónicos de Filosofia del Derecho, n.15, 2007 (14 p.)

LARIGUET, Guillermo. Conflictos trágicos genuinos, ponderación y límites de la racionalidad jurídica: en torno a algunas ideas de Manuel Atienza. Isonomía, n.24, abril 2006, p.93-113.

PULIDO, Carlos Bernal. Estructura y límites de la ponderación. Revista Doxa: Cuadernos de Filosofía del Derecho, n.26. Universidad de Alicante, 2003, p.8.

SILVA, Virgílio Afonso. Comparing the incommensurable: constitutional principles, balancing and rational decision. Oxford Journal of Legal Studies, vol.31, n.2 (2011), pp. 273-301. Published advance access March 17, 2011.

TOLEDO, Cláudia. Hard cases, rationality and transformation of the legal order. In: XXVIII World Congress of the International Association for the Philosophy of Law and Social Philosophy (IVR). Lisboa, 2017. 